\title{
Flow fields around ciliated larvae: effects of natural and artificial tethers
}

\author{
Richard B. Emlet* \\ Department of Zoology, University of California, Berkeley, California, USA \\ and \\ Department of Zoology and Friday Harbor Laboratories, University of Washington, USA
}

\begin{abstract}
The effects of tethering planktonic organisms on the swimming and feeding currents they produce were examined in 2 different ways. Larvae of the bivalve Crassostrea gigas and the gastropod Calliostoma ligatum were tethered in a miniature flow tank in still water and in water flowing at the approximate swimming speed of the organisms. The currents produced by the velar cilia of these larvae were filmed at 200 frames $\mathrm{s}^{-1}$, using algal cells as markers to visualize fluid movement under these 2 conditions. Larvae of the polychaete Mesochaetopterus taylori were filmed at 200 frames s$^{-1}$ while swimming and while tethered to a microscope slide by their own mucus. The tethered bivalve larvae in still water and the tethered polychaete larvae generated flow fields in which particles followed curved trajectories. In contrast particles followed straighter trajectories around freely swimming polychaete larvae and the bivalve larva tethered in flowing water. For one $C$. gigas larva, angular velocities of prototrochal cilia were not significantly different under the 2 conditions. Calculations indicate that in still water this larva moved ca $20 \%$ less water through the velar cilia per unit time than when in flowing water. For the polychaete, the cilia of tethered larvae beat more slowly than those of freely swimming larvae. For all 3 experimental animals, shear of water around cilia, estimated from ciliary angular velocities and particle velocities, was greater for tethered larvae in still water than for those in flowing water or for freely swimming larvae. These changes in flow field, flux through the ciliated layer, and shear of water around cilia all have quantitative effects on rates of feeding calculated from observations on tethered organisms, but effects depend on the mechanism of particle capture utilized. There is no evidence that mechanisms of particle capture are changed as a result of tethering. Because buoyancy and body drag act as partial tethers, results of this study indicate how flow fields can be changed around small, elaborately shaped, planktonic organisms, and at the scale of feeding appendages. Hydrodynamic changes that occur simply as a result of being free swimming or tethered may also have influenced the evolution of body shape and feeding mechanisms of organisms that changed from free living to sessile (or vice versa).
\end{abstract}

\section{INTRODUCTION}

Suspension feeding is extremely common among aquatic invertebrates, including large and small, sessile and mobile organisms (e.g. Jørgensen 1966, LaBarbera 1984). Many of these organisms use cilia or setous appendages to create a feeding current, to remove particles from that current, and to ingest or to reject food particles (e.g. Fenchel 1986, Strathmann 1987). For sessile suspension feeders, the fiberlike appendages create only feeding currents. For many planktonic suspension feeders, the same fiberlike

\footnotetext{
- Present address: Dept of Biological Sciences, University of Southern California, Los Angeles, California 90089-0371, USA
}

appendages used in feeding also create the swimming currents. If other factors are held constant the flow field created by a stationary organism will be different from that produced by the same organism that moves as a result of producing these currents. This is purely a consequence of changes in the balance of forces in the 2 conditions (Wu 1977, Keller \& Wu 1977, Childress et al. 1987). Differences in the flow may include geometry of the flow field, current velocity, and shear of the water past appendages that produce the current. Do these differences affect rates of particle encounter and mechanisms of particle capture?

Sessile organisms, by definition, are attached to substrata and thus may be considered as being naturally tethered in place. Mobile organisms may also experience natural retarding forces such as drag and gravity 
which act as incomplete or partial tethers to impede movement (Strickler 1982, Emlet \& Strathmann 1985). Artificial tethering is commonly employed to study feeding mechanisms of small mobile organisms (e.g. marine invertebrate larvae and zooplankton) that must be viewed through a microscope (Strathmann \& Leise 1979, Alcaraz et al. 1980, Koehl \& Strickler 1981, Paffenhöfer et al. 1982, Price et al. 1983, Yule \& Crisp 1983, Gallager 1988). Tethering is required to observe simultaneously the movement of appendages, particles and water. Because these results are extrapolated to swimming organisms, it is important to evaluate how tethering may affect the results. The present study examines how tethering influences the flow field at the level of the organism down to the level of the appendages which produce the current.

Because of the small size of cilia and setous appendages and their relatively slow movement, the viscous interactions of water with moving appendages determine the production and maintenance of the feeding current and influence particle capture mechanisms (LaBarbera 1984). Cilia or setous appendages create a current by sweeping through the water. The viscous layers of water surrounding a moving fiber and a food particle reduce the likelihood of direct contact between appendage and particle. Appendages that produce currents may actually capture particles by a number of mechanisms including active change of motion to entrain the particle with its surrounding parcel of water on a path toward the mouth, direct interception, and sieving (Strathmann et al. 1972, Koehl \& Strickler 1981, Price et al. 1983, LaBarbera 1984, Price \& Paffenhöfer 1985, Fenchel 1986). Because natural or artificial tethers may change the current velocity and shear of water past the appendages, it is also important to determine how this affects the volume of water and particles moving through the region where particles are captured, and the mechanisms of capture.

To examine the consequences of tethering, ciliated larvae of the bivalve Crassostrea gigas, the gastropod Calliostoma ligatum and the polychaete Mesochaetopterous taylori were filmed at 200 frames $\mathrm{s}^{-1}$; freely swimming, tethered in a current to mimic free swimming, or tethered without an ambient current. Though the larvae of C. ligatum do not feed and the mechanism of feeding is not known for the larval stage of the polychaete used in this study (but see Werner 1953), the results allow comparison between swimming and tethered conditions that may apply generally to other small, self-propelled organisms.

\section{MATERIALS AND METHODS}

Studies on larvae of Crassostrea gigas and Calliostoma ligatum. High speed films were made of the flow field and the velar cilia with which bivalve and gastropod larvae swim and feed (see 'Discussion' for description of feeding). Flow fields around pediveliger larvae (shell length, $330 \mu \mathrm{m}$ ) of Crassostrea gigas (Thunberg) were studied with the larvae tethered in a tank in still water and in flowing water moving at the speed that untethered larvae swim. The larvae were always oriented so that the flowing water moved past them in a manner similar to the actual swimming current. Swimming speeds were determined from video tapes of individuals swimming freely in a horizontal plane in a dish, $40 \mathrm{~mm}$ in diameter, containing $30 \mathrm{ml}$ of seawater (depth $15 \mathrm{~mm}$ ). A mean swimming speed of $1.5 \mathrm{~mm} \mathrm{~s}^{-1}\left(0.62 \mathrm{~mm} \mathrm{~s}^{-1} \mathrm{SD}, \mathrm{n}=14\right)$ was calculated for C. gigas larvae at $21.5^{\circ} \mathrm{C}$. Newly hatched veligers (shell length $350 \mu \mathrm{m}$ ) of Calliostoma Ligatum (Gould) were also tethered in a flow tank in still water and in flowing water. Swimming speed of C. ligatum was not measured. However, the mean horizontal swimming speeds for larvae of 2 other gastropods, Ilyanassa obsoleta and Lacuna sp., were measured as $2.2 \mathrm{~mm} \mathrm{~s}^{-1}\left(0.51 \mathrm{~mm} \mathrm{~s}^{-1} \mathrm{SD}, \mathrm{n}=14\right)$ and $4.0 \mathrm{~mm} \mathrm{~s}^{-1}$ (0.43 $\left.\mathrm{mm} \mathrm{s}^{-1} \mathrm{SD}, \mathrm{n}=8\right)$, respectively, and the water speed during studies on C. ligatum was in this range.

Individual larvae were tethered by attaching their shells to tapered glass rods with cyanoacrylate glue. A larva was isolated in a drop of water, and the water was removed carefully with tissue paper. Immediately, a glass rod was dipped in a minute amount of cyanoacrylate glue and then touched to the shell of the larva. Subsequently, the glass rod and attached larva were immersed in filtered seawater. Tethered larvae were observed periodically to evaluate their swimming condition. They usually remained healthy for several days after which they were lost due to a weakening of the adhesive bond between the glass rod and larval shell.

A miniature recirculating flow tank $(8 \mathrm{~cm}$ long $\times 4$ $\mathrm{cm}$ wide $\times 1 \mathrm{~cm}$ deep) with a horizontal working area of $1 \mathrm{~cm}^{2}$ was used to create currents past the tethered larva (see Fig. 1 for details). The flow tank was mounted on the stage of a compound microscope with Differential Interference Contrast optics and a trinocular head. Videotapes or high-speed films of the flow field past the larvae could then be recorded. To attain optical clarity of cilia and particles, a larva had to be tethered within $2 \mathrm{~mm}$ of the cover glass bottom of the flow tank. Though the optical quality was increased by moving the larva closer to the bottom of the tank, larvae were positioned ca $1.5 \mathrm{~mm}$ above the tank bottom because this distance corresponded with the height of full development of the boundary layer over the bottom of the tank (see Fig. 1 insert). All other walls of the tank were at least $15 \mathrm{~mm}$ away.

Flow fields around tethered larvae were recorded on Kodak $4 \mathrm{X}$ negative cine film (ca 200 frames $\mathrm{s}^{-1}$ ) with a 
Fig. 1. Miniature flow tank in which tethered larvae were filmed. Current was produced by a pressure head created with an air lift (al) that moved water from the downstream (d) to the upstream $(\mathrm{u})$ reservoir Valves (v) located at the entrance (en) and exit (ex) to the flow tank were used to control current speed; baffles (b) at the entrance and exit to the tank made flow more uniform across the width of the tank. Insert shows the velocity profile up from the bottom of the tank in the region where larvae were tethered. Means and standard error bars are plotted at each height. This velocity profile was determined by videotaping $20 \mu \mathrm{m}$ particles passing through the working area of the tank. Velocities of at least 10 particles for each height were measured to the nearest $0.01 \mathrm{~mm} \mathrm{~s}^{-1}$ at $0.01,0.15,0.33 \mathrm{~mm}$ heights above the bottom and then at $0.33 \mathrm{~mm}$ intervals to a height of 4 $\mathrm{mm}$ above the tank bottom. Videotapes were analyzed with EXPERTVISION hardware and software (Motion Analysis Corp.)

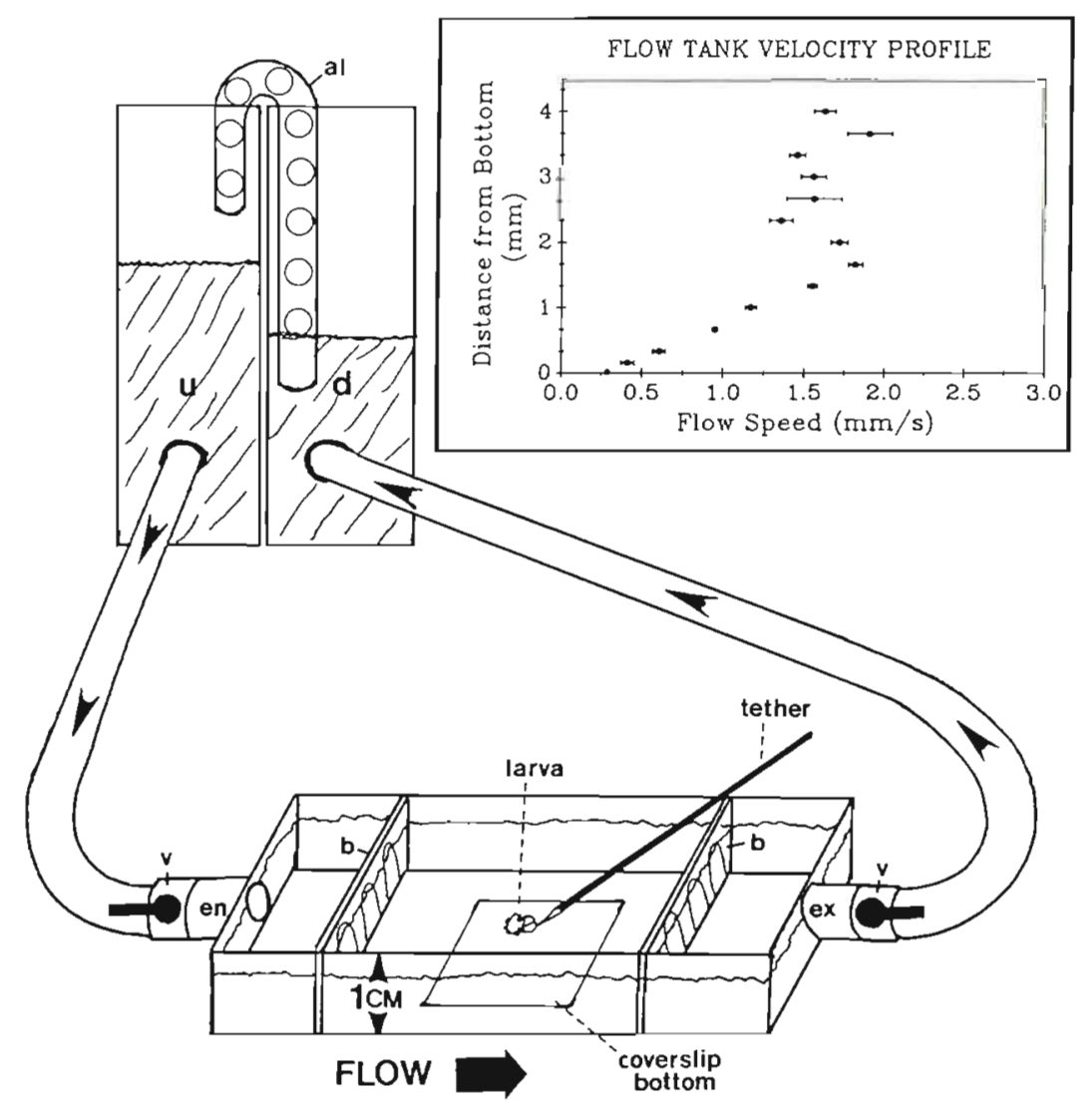

Locam cine camera. A timing light marked the edge of the film every $0.01 \mathrm{~s}( \pm 1 \%$ precision according to the camera's manufacturer, Redlake Corporation). Algal cells of Isochrysis galbana (mean diameter $5.5 \mu \mathrm{m} \pm$ $0.5 \mu \mathrm{m} \mathrm{SD}$ ) were used to mark the fluid. Prior to filming, algal cells were centrifuged to remove culture medium and were resuspended in filtered seawater. Several drops of cell suspensions were then introduced upstream of the tethered animal. Observations on the flow field were made in a horizontal plane extending approximately one body length upstream and $1 \mathrm{~mm}$ to one side of tethered Crassostrea gigas and $300 \mu \mathrm{m}$ to one side of tethered Calliostoma ligatum. Studies with larvae of $\mathrm{C}$. gigas were conducted at $20^{\circ} \mathrm{C} \pm 2^{\circ}$ and those with larvae of $C$. ligatum were conducted at 14 to $15^{\circ} \mathrm{C}$.

Studies on larvae of Mesochaetopterus taylori. A second study examined the effects of tethering by observing flow fields around freely swimming and selftethered larvae of the polychaete Mesochaetopterus taylori Potts. Larvae were $3 \mathrm{wk}$ old and 220 to $275 \mu \mathrm{m}$ in length. Their stage of development was intermediate between the trochophore and metatrochophore stages and similar to that described for Chaetopterus variopedatus by Cazaux (1965, Plate 2). Larvae were uniformly covered with cilia, but 4 transverse rows of longer cilia stood out because they showed diaplectic metachrony. The first two of these bands were located near the anterior third of the body near the mid and lower region of the mouth. The third band, the metatrochal band, was located at the widest region of the body midway between anterior and posterior ends. The last band was near the posterior end, just anterior to the caudal papilla (for ciliated band locations see Fig. $2 \mathrm{C}$, D). In later developmental stages the metatrochal band is the strongly developed swimming band of the larva.

Larva were filmed (with the same Locam cine camera described above) while swimming in a layer of seawater ca $1 \mathrm{~mm}$ thick between a microscope slide and a cover glass raised above the slide with small feet of clay. Larvae of Mesochaetopterus taylori swam in the layer of seawater for 10 to $15 \mathrm{~min}$ after being introduced to the microscope slide. Because they usually swam in a straight line, it was possible to line up the slide and start filming, so that the camera was filming at 200 frames $\mathrm{s}^{-1}$ when larvae swam into the field of view. As larvae swam they continuously produced strings of mucus at their posterior ends. Eventually each larva became effectively tethered to the microscope slide by its own strand of mucus, and then could be filmed while stationary with actively beating cilia. Plastic beads $2 \mu \mathrm{m}$ in diameter were used to visualize 
currents produced by cilia. During filming, the whole preparation was kept at 12 to $13^{\circ} \mathrm{C}$ by a continuous flow of water through a hollow cooling slide beneath the specimen. The cooling slide was modified from a design by Stevens (1973). The mean swimming speeds of larvae in 2 sequences were $406 \mu \mathrm{m} \mathrm{s}^{-1}\left(106 \mu \mathrm{m} \mathrm{s}^{-1}\right.$ $\mathrm{SD}, \mathrm{n}=19$ frame intervals $)$ and $304 \mu \mathrm{m} \mathrm{s}^{-1}\left(83 \mu \mathrm{m} \mathrm{s}^{-1}\right.$ $\mathrm{SD}, \mathrm{n}=18$ frame intervals).

For larvae of Mesochaetopterus taylori observations on the flow field were made in a horizontal plane extending ca $150 \mu \mathrm{m}$ away from each specimen. The distance between each larva and the nearest boundary was about $450 \mu \mathrm{m}$. Though wall effects of the microscope slide and cover glass probably modify the velocity profiles, both tethered and swimming larvae were observed under similar conditions

Analysis of high speed films. Films of all 3 species were analyzed, frame by frame, with a stop-motion projector by digitizing points on the organism, particles in the fluid, and timing marks on the film One $30 \mathrm{~m}$ roll of film, containing 4 sequences 600 to 900 frames each), was analyzed for one larva of Crassostrea gigas, and another $30 \mathrm{~m}$ roll of film containing 2 sequences (ca 1880 frames each), was analyzed for one larva of Calliostoma ligatum. Film speed (frames $\mathrm{s}^{-1}$ ) was determined as the distance between adjacent timing marks (distance/mark), divided by the height of a frame (distance/frame), divided by the time between each timing mark $(0.01 \mathrm{~s} /$ mark $)$. For each sequence, mean film speed was determined from 9 measurements ( 3 measurements each, at the beginning, middle and end of the region of the sequence where film speed was constant). For sequences included in the present study the coefficients of variation ( $\mathrm{SD} /$ mean) of film speeds were between 0.5 and $0.9 \%$. The inverse of the mean film speed was used as the time interval between frames within a sequence.

Films were projected onto paper and positions of particles were mapped as they passed the organisms. Particle velocities were determined as they crossed a line perpendicular to the flow direction and intersecting the ciliated region of the velum. Particle positions within 1 cilium length of the perpendicular line were used to calculate particle velocity, thus a given particle was tracked over 3 to 11 (usually 5 to 7 ) consecutive frames. Velocities were determined by dividing the distance a particle traveled by the time interval of the recorded distance. The distance of a particle from the surface of the body was measured at the position that the particle crossed this line. Velocity profiles are reported in the reference frame of the larvae (velocity of the body surface is zero) and represent the velocity of particles as they passed through the above mentioned line. The precision of measurement was determined by making 10 replicate measurements of each of 5 particle paths and of each of 5 distances from the velar surface. These replicate measurements had coefficients of variation (SD/mean) that did not exceed $1.4 \%$.

One $30 \mathrm{~m}$ roll of film of Mesochaetopterus taylori containing sequences of 2 swimming larvae and sequences of 3 self-tethered larvae was analyzed. Each sequence where data was collected was 200 to 300 frames long. Digitized point coordinates were fed directly into a computer program that gave position and velocity vectors of the larva and surrounding particles. Transects of particle velocities were taken moving out radially from the metatrochal band and for one swimming larva from the first (prototrochal) band. A series of 10 replicates of the same sequence of film ( 6 frame intervals) were compared for swimming speed and particle velocity in order to determine the limit on digitizing precision. Measurements of swimming speeds varied from mean swimming speed by as much as $\pm 40 \mu \mathrm{m} \mathrm{s}^{-1}$, ca $10 \%$ of the swimming speed. The coefficients of variation ( $\mathrm{SD} / \mathrm{mean}$ ) for particle velocities did not exceed $11 \%$. Because particle velocities were not different within sequences of 2 swimming larvae or within sequences of 3 self-tethered larvae, the data were pooled for comparison between the free swimming and self-tethered cases.

Angular velocities of cilia on the power stroke in the prototrochal ciliary bands of Crassostrea gigas and Calliostoma ligatum and in the prototrochal and metatrochal ciliary bands of Mesochaetopterus taylori were determined from tracings of cilia by measuring the angle through which cilia moved and the time interval between consecutive frames. Angular velocities were measured during the middle of the power stroke. The radius of arc of a cilium is an estimate of cilium length and was measured as the distance between the cilium tip and the point of rotation at the cilium base. These methods of measuring cilium angular velocity and approximate cilium length were used by Strathmann \& Leise (1979).

\section{RESULTS}

\section{Trajectories of particles}

Crassostrea gigas. For the tethered bivalve larva in flow (which simulated a freely swimming individual), particles moved in approximately straight lines indicating fluid moved along straight streamlines, parallel to the direction of swimming (Fig. 2A). Particles directly in front of the organism (along the path of swimming) were deflected radially outward as they approached the velum. These particles (and fluid) moved past the larva through the ciliated region of the velum. In addition, particles from a small, upstream, region ( $\mathrm{R}$ in Fig. 

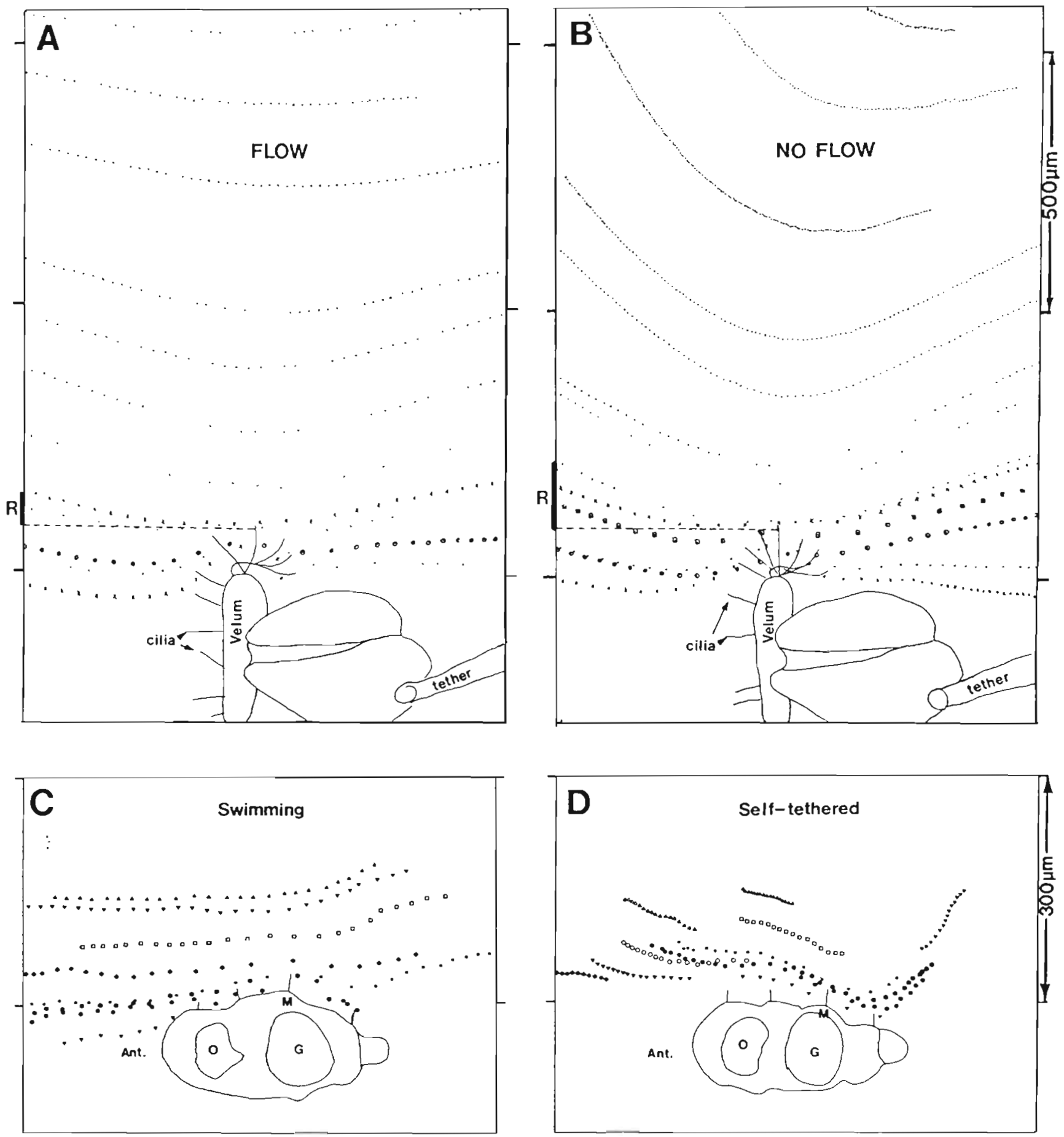

Fig. 2. (A, B) Crassostrea gigas. Particle trajectories around tethered larvae (A) in ambient flow approximating natural swimming speed, and (B) with no ambient flow. Particles move from left to right. Symbols distinguish different particles following trajectories that are close to one another or overlap. Approximate time between consecutive positions of particles is $10 \mathrm{~ms}$, except for the 2 most distant particles for the larva in No-flow where the time is $20 \mathrm{~ms}$. See text for explanation of R. (C, D) Mesochaetopterus taylori. Particle trajectories around freely swimming and self-tethered larvae. Particles move from left to right. Different symbols represent individual particles. Time interval between consecutive particle positions is $40 \mathrm{~ms}$. Other symbols: Ant., anterior; $O$, oral cavity, G, gut; $M$, metatrochal cilia. Small vertical lines indicate location of ciliary bands 
2A) outside the direct swimming path of the larva also moved though the ciliated layer of the velum.

For the tethered bivalve larva in still water, the velar cilia created a flow field in which particles moved along curved paths, convex toward the larva's ventral-dorsal axis (Fig. 2B). Curved particie trajectories indicate that upstream particles well outside the cross-sectional area and swimming path of the larva move radially in toward it and pass through the ciliated region of the velum. As an indication of how different the particles paths are in these 2 cases, upstream regions, outside the projected area of the larva ( $R$ in Fig. 2A, B) can be compared at a distance of one body length upstream. For the larva in flow, $\mathrm{R}$ is $1 / 5$ of the radius of the approximately circular area through which particles move and pass through the velar cilia. For the tethered larva in still water, $\mathrm{R}$ is $2 \times$ larger than $\mathrm{R}$ for the one in flow, or $1 / 3$ the radius of the approximately circular area. Because of these differences in $\mathrm{R}$, the tethered larva in still water when compared to that in flowing water has a $50 \%$ larger area one body length upstream through particles move that later pass through the ciliary layer of the velum.

Mesochaetopterus taylori. The flow fields around freely swimming and self-tethered polychaete larvae showed patterns similar to those seen around the bivalve larvae. For the freely swimming larvae particles followed straighter paths than particles around selftethered larvae (Fig. 2C, D). For the latter, particle paths showed a greater curvature, convex toward the long axis of the larvae. Because of limited numbers of particle paths, the difference could not be quantified as it was for larvae of Crassostrea gigas.

\section{Flow velocities above and within the ciliated region}

Crassostrea gigas and Calliostoma ligatum. For both species, whether tethered in still water or in flowing water, particles moved most rapidly in the ciliated layer (Fig. 3A, C). Relative to the surface of the larva, particle velocities increased from zero (due theoretically to the no-slip condition, but not measured in this study) at the velar surface to a maximum near the tips of the cilia. For both species and both tethered cases, the velocity gradients in the ciliary layer were extremely steep with particle velocities reaching $10 \mathrm{~mm} \mathrm{~s}^{-1}$ less than $90 \mu \mathrm{m}$ away from the velar edge for Crassostrea gigas and $9 \mathrm{~mm} \mathrm{~s}^{-1}$ at $110 \mu \mathrm{m}$ from the velar edge for Calliostoma ligatum. Due to limitations of filming, few or no particles were observed in the region of the ciliary recovery stroke, immediately adjacent to the larva's surface. Because cilia were moving upstream at this location, the velocity gradients were probably even steeper than shown in Fig. 3A, C. At a greater distance from the larva's surface, there was a gradient of particle velocities down to the ambient current in the flow tank. For C. gigas tethered in flowing water, the particle motion dropped to the swimming speed of the organism; while for the same larva in still water, particle velocity dropped to zero (Fig. 3A). Due to the higher magnification of the film of $C$. ligatum, particle velocities were still above ambient current at the outer edge of the filming frame (Fig. 3C).

Flow conditions within the ciliated layer were different for the tethered larvae in flowing water and in still water (Fig. 3B, D). For the larva of Crassostrea gigas, these differences in particle velocities were not attributable to differences in velocity of cilia. For each particle that passed through the ciliary layer, angular velocity of a nearby cilium was also measured. The angular velocities of cilia for the tethered larvae in flowing water and still water were not statistically different, though the mean was slightly higher for that in still water (Table $1 \mathrm{~A}$ ).

Within the ciliary layer, particle velocity as a function of height above the larva's surface was characterized by a large variance. For Crassostrea gigas, this large variance together with the restricted range over which particle velocities were measured in the ciliary layer probably explain why linear regressions of particle velocity versus distance from the surface of the larva did not have slopes significantly different from zero for either the flow or the no-flow case (Table 1B). At a given height above the surface, there was up to a 2 or 3 -fold variation in particle velocity (Fig. 3B). Varying particle velocity was probably due to different phases of ciliary beat at the particular place and time that a particle was passing through the ciliated region. Particles traveling rapidly were probably near cilia on power strokes, whereas particles traveling more slowly may have been passing through a region where nearby cilia were on their recovery strokes. The data in Fig. 3B also indicate that the region of most rapid particle motion was within the ciliary layer and not at the tips of the cilia. Because linear regressions were not significant, data on particle velocities for each case were compared by t-test only for the region in the ciliary layer where data overlapped (Table 1A). Results indicate that mean particle velocity was higher in the ciliated region for the tethered larva in flow than for that in still water

For the larva of Calliostoma ligatum, ciliary angular velocity was higher for the tethered larva when in still water than when in flowing water (Table 2A). For this larva, with prototrochal cilia over $126 \mu \mathrm{m}$ in length (Table 2A), the particle velocities in the ciliary layer increased significantly as a function of distance from the velar edge (Table 2B, Fig. 3D). Despite a lower ciliary angular velocity for the larva in flowing water, particle velocities (elevations of the regressions) were 
Fig. 3. Particle velocity versus distance from velar edge for (A, B) Crassostrea gigas and $(C, D)$ Calliostoma ligatum in ambient flow approximating natural swimming speed and with no ambient flow. (A, C) Velocity profile out from larva. $(B, D)$ Particle velocities in the ciliated layer. Each data point is a for separate particle that crossed a line perpendicular to flow at the level of the ciliated region of the velum
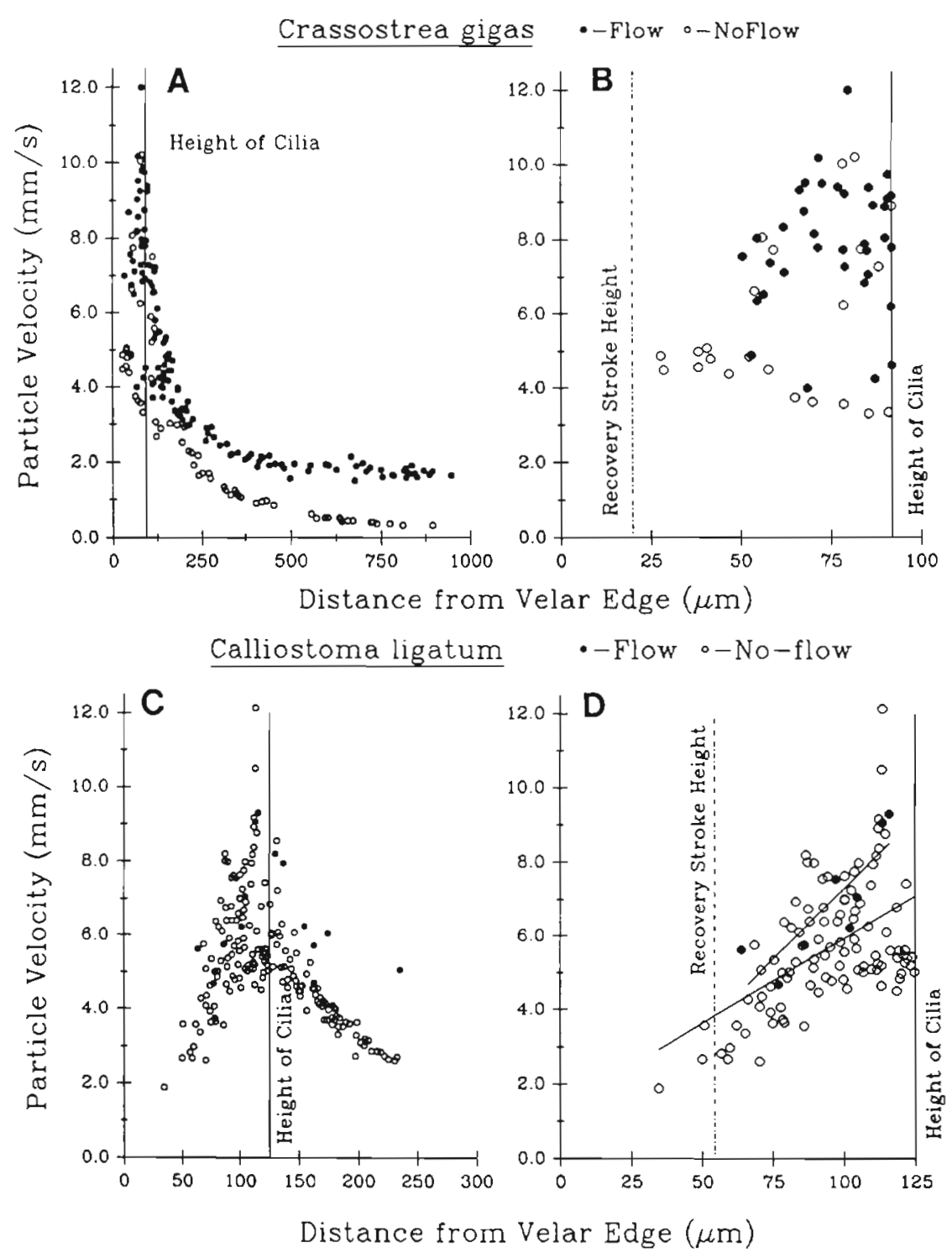

actually higher than those for the larva in still water (Table 2A, Fig. 3D). As with the bivalve larva, maximum particle velocities for $C$. ligatum were proximal to the tips of the cilia.

Mesochaetopterus taylori. Velocity gradients on a line out from the metratrochal band and perpendicular to the long axis of the larval body were examined in the frame of reference of the larva, with velocity of the specimen's surface zero. For the swimming larvae, the water velocity relative to the larva increased from $0 \mu \mathrm{m}$ $\mathrm{s}^{-1}$ (theoretically) at the larva's surface to ca $1600 \mu \mathrm{m}$ $\mathrm{s}^{-1}$ at a distance of $30 \mu \mathrm{m}$, still within the ciliary layer (Fig. 4A). Well out beyond the reach of cilia, at a distance of ca $140 \mu \mathrm{m}$ from the larva's surface, the water velocity had dropped to the swimming speed of the larva. Though not pictured in the figures, data for the velocity gradient out from the prototrochal band was similar to that for the metatrochal band. The velocities relative to the surface of the larva around selftethered larvae were not as rapid as those around freely swimming individuals. Water velocity reached a peak of ca $800 \mu \mathrm{m} \mathrm{s}^{-1}$ at a distance less than $20 \mu \mathrm{m}$ from the larva's surface and beyond this point velocity decreased to $0 \mu \mathrm{m} \mathrm{s}^{-1}$ about $100 \mu \mathrm{m}$ away (Fig. 4B). As with films of Crassostrea gigas, few particles passed near the polychaete larval surfaces and flow in the recovery stroke region could not be defined.

Unlike the data for Crassostrea gigas, differences in particle velocities around freely swimming and selftethered polychaete larvae were due to differences in size and speed of cilia as well as tethering. The freely swimming larvae on the films were up to $15 \%$ longer than tethered larvae; a mean of $260 \mu \mathrm{m}$ for swimming larvae $(n=2)$ and a mean of $232 \mu \mathrm{m}(\mathrm{n}=3)$ for tethered 
Table 1A. Crassostrea gigas (shell length, $330 \mu \mathrm{m}$ ). Data and statistics for lengths of cilia and velocities of cllia and particles. Values are means, SE, and (sample size)

\begin{tabular}{|c|c|c|c|}
\hline & Flow & No-Flow & Stat. test (Sign. level) \\
\hline Cilium length $(\mu \mathrm{m})$ & \multicolumn{2}{|c|}{$91.5 \pm 1.2(20)$} & \\
\hline Recovery stroke height $(\mu \mathrm{m})$ & \multicolumn{2}{|c|}{$20.1 \pm 0.6(10)$} & \\
\hline Cilium angular velocity $\left(\mathrm{rad} \mathrm{s}^{-1}\right)$ & $\begin{array}{c}151.5 \pm 3.5 \\
(36)\end{array}$ & $\begin{array}{c}159.7 \pm 5.43 \\
(23)\end{array}$ & $\begin{array}{c}\text { t-test, } \mathrm{t}=1.332 \\
(\mathrm{p}>0.10)\end{array}$ \\
\hline Particle velocity ${ }^{2}\left(\mathrm{~mm} \mathrm{~s}^{-1}\right)$ & $\begin{array}{c}7.92 \pm 0.29 \\
(36)\end{array}$ & $\begin{array}{c}6.24 \pm 0.61 \\
(16)\end{array}$ & $\begin{array}{c}\text { t-test, } \mathrm{t}=2.842 \\
(\mathrm{p}<0.01)\end{array}$ \\
\hline Relative velocity ${ }^{b, c}\left(\mathrm{~mm} \mathrm{~s}^{-1}\right)$ & $\begin{array}{c}2.88 \pm 0.35 \\
(36)\end{array}$ & $\begin{array}{l}5.29 \pm 0.45 \\
(23)\end{array}$ & $\begin{array}{c}\text { ANCOVA, } \\
\text { slopes } F=0.004(p>0.5) \\
\text { elevation } F=16.325(p<0.001)\end{array}$ \\
\hline Cilium/Particle velocity ${ }^{c}$ & $\begin{array}{c}1.40 \pm 0.11 \\
(36)\end{array}$ & $\begin{array}{c}2.07 \pm 0.14 \\
(23)\end{array}$ & $\begin{array}{c}\text { ANCOVA } \\
\text { slopes } F=1.096(p>0.5) \\
\text { elevation } F=13.991(p<0.001)\end{array}$ \\
\hline \multicolumn{4}{|c|}{$\begin{array}{l}\text { Particle velocity was determined in the ciliary layer and only for the region of overlap of the } 2 \text { data sets, from } 50 \text { to } 92 \text { um ou } \\
\text { from the velar surface } \\
\text { fhis value } 1 \text { determined within the ciliary layer only. Relative velocity = (Cilium angular velocity } \times \text { Distance of a particle } \\
\text { from the surface of the organism) - (Particle velocity) } \\
\text { "Values reported are adjusted means and adjusted standard errors based on ANCOVA }\end{array}$} \\
\hline
\end{tabular}

Table 1B. Crassostrea gigas larva. Regression information

\begin{tabular}{|c|c|c|c|c|}
\hline Condition & Equation & $\mathrm{r}^{2}$ & $\mathrm{p}$ & $\mathrm{n}$ \\
\hline \multicolumn{5}{|c|}{ Particle velocity, $\mathrm{mm} \mathrm{s} \mathrm{s}^{-1}(\mathrm{Y})$ vs Distance from surface in ciliary layer, $\mu \mathrm{m}(\mathrm{X})$} \\
\hline $\begin{array}{l}\text { Flow } \\
\text { No-flow }\end{array}$ & $\begin{array}{l}Y=0.016 X+6.76 \\
Y=0.034 X+3.67\end{array}$ & $\begin{array}{l}0.014 \\
0.108\end{array}$ & $\begin{array}{l}>0.50 \\
>0.20\end{array}$ & $\begin{array}{l}36 \\
23\end{array}$ \\
\hline \multicolumn{5}{|c|}{ Relative velocity ${ }^{b} \mathrm{~mm} \mathrm{~s}^{-1}(\mathrm{Y})$ vs Distance from surface, $\mu \mathrm{m}(\mathrm{X})$} \\
\hline $\begin{array}{l}\text { Flow } \\
\text { No-flow }\end{array}$ & $\begin{array}{l}Y=0.128 X-6.15 \\
Y=0.130 X-3.90\end{array}$ & $\begin{array}{l}0.398 \\
0.636\end{array}$ & $\begin{array}{l}<0.001 \\
<0.001\end{array}$ & $\begin{array}{l}36 \\
23\end{array}$ \\
\hline \multicolumn{5}{|c|}{$\begin{array}{l}\text { Cilium velocity/Particle velocity }(Y) \text { vs Distance from surface, } \mu m(X) \\
\text { (Based on measured cilium angular velocity with each particle) }\end{array}$} \\
\hline $\begin{array}{l}\text { Flow } \\
\text { No-flow }\end{array}$ & $\begin{array}{l}Y=0.017 X+0.22 \\
Y=0.028 X+0.13\end{array}$ & $\begin{array}{l}0.168 \\
0.362\end{array}$ & $\begin{array}{l}<0.05 \\
<0.005\end{array}$ & $\begin{array}{l}36 \\
23\end{array}$ \\
\hline \multicolumn{5}{|c|}{ (Based on mean cilium velocity) } \\
\hline $\begin{array}{l}\text { Flow } \\
\text { No-flow }\end{array}$ & $\begin{array}{l}Y=0.019 X+0.09 \\
Y=0.028 X+0.19\end{array}$ & $\begin{array}{l}0.235 \\
0.338\end{array}$ & $\begin{array}{l}<0.01 \\
<0.01\end{array}$ & $\begin{array}{l}36 \\
23\end{array}$ \\
\hline
\end{tabular}

larvae. Though the stages appeared equivalent, the cilia on one freely swimming larva were longer than those on one stationary larva (Table 3A). Both prototrochal and metatrochal cilia on the freely swimming larvae had higher angular velocities than these cilia on tethered larvae (Table 3A). The lower angular velocity and shorter length of cilia on the tethered larvae are 2 reasons that water velocities around tethered larvae were lower than around swimming larvae (Fig. 4). It is not clear why ciliary angular velocities were lower for the tethered specimens. These larvae swam until they became tethered in place by their own mucous strand and may have been less active than freely swimming larvae at the time of filming. Reduced activity of tethered larvae may have been physiological or behavioral. However, cilia on tethered larvae still showed metachrony, and the larvae appeared healthy. On both the swimming and tethered larvae, mean angular velocities of the prototrochal cilia were ca $60 \%$ of the mean angular velocities of the metatrochal cilia.

\section{Estimated volume flux through the ciliated region: Crassostrea gigas}

The velocity profiles of particles can be used to estimate the volume flux (volume/time) of water through a unit length of the ciliated band of the velum. Although 
Table 2A. Calliostoma ligatum (shell length, $350 \mu \mathrm{m}$ ). Data and statistics for lengths of cilia and velocites of cilia and particles. Values are means, SE, and (sample size)

\begin{tabular}{|c|c|c|c|}
\hline & Flow & No-Flow & Stat. test \\
\hline Cilium length $(\mu \mathrm{m})$ & \multicolumn{2}{|c|}{$126.6 \pm 3.0(15)$} & \\
\hline Recovery stroke height $(\mu \mathrm{m})$ & \multicolumn{2}{|c|}{$54.4 \pm 2.4(10)$} & \\
\hline Cilium angular velocity $\left(\mathrm{rad} \mathrm{s}^{-1}\right)$ & $\begin{array}{c}107.8 \pm 6.7 \\
(8)\end{array}$ & $\begin{array}{c}130.5 \pm 4.4 \\
(8)\end{array}$ & $\begin{array}{l}\text { Mann-Whitney } \\
U=9(p<0.02)\end{array}$ \\
\hline Particle velocity ${ }^{\mathrm{a}}\left(\mathrm{mm} \mathrm{s}^{-1}\right)$ & $6.91 \pm 0.51$ & $5.72 \pm 0.14$ & $\begin{array}{l}\text { ANCOVA } \\
\text { slopes } F=1.028(p>0.3) \\
\text { elevation } F=5.202(p<0.03)\end{array}$ \\
\hline Cilium/Particle velocity ${ }^{b}$ & $1.51 \pm 0.07$ & $\begin{array}{c}2.15 \pm 0.05 \\
(82)\end{array}$ & $\begin{array}{l}t=\text { test, } t=3.777 \\
(p<0.001)\end{array}$ \\
\hline \multicolumn{4}{|c|}{$\begin{array}{l}\text { a Particle velocity was determined in the ciliary layer, and values reported are adjusted means and adjusted standard errors } \\
\text { based on ANCOVA. } \\
{ }^{\circ} \text { Values used are those from the region of overlap of the } 2 \text { data sets, } 62 \text { to } 114 \mu \mathrm{m} \text { out from the velar edge }\end{array}$} \\
\hline
\end{tabular}

Table 2B. Calliostoma ligatum larvae. Regression information

\begin{tabular}{|c|c|c|c|c|}
\hline Condition & Equation & $r^{2}$ & $\mathrm{p}$ & $\mathrm{n}$ \\
\hline \multicolumn{5}{|c|}{ Particle velocity, $\mathrm{mm} \mathrm{s}^{-1}(\mathrm{Y})$ vs Distance from surface in ciliary layer, $\mu \mathrm{m}(\mathrm{X})$} \\
\hline Flow & $Y=0.077 X-0.44$ & 0.719 & $<0.01$ & 8 \\
\hline No-flow & $\mathrm{Y}=0.046 \mathrm{X}+1.32$ & 0.277 & $<0.001$ & 103 \\
\hline \multicolumn{5}{|c|}{ Cilium velocity/Particle velocity $(Y)$ vs Distance from surface, $\mu \mathrm{m}(\mathrm{X})$ (Based on mean cilium velocity) } \\
\hline Flow & $Y=-0.000 X+1.537$ & 0.001 & $>0.95$ & 8 \\
\hline No-flow & $Y=0.005 X+1.764$ & 0.040 & $<0.05$ & 103 \\
\hline
\end{tabular}

Fig. 4. Mesochaetopterus taylori. Particle velocity around (A) freely swimming larvae and (B) self-tethered larvae. Velocities are in the direction parallel to the long axis of the larval body and measured along a transect out from the metatrochal cilia. Different symbols represent data from different sequences of high speed film. Each data point is for a separate particle.

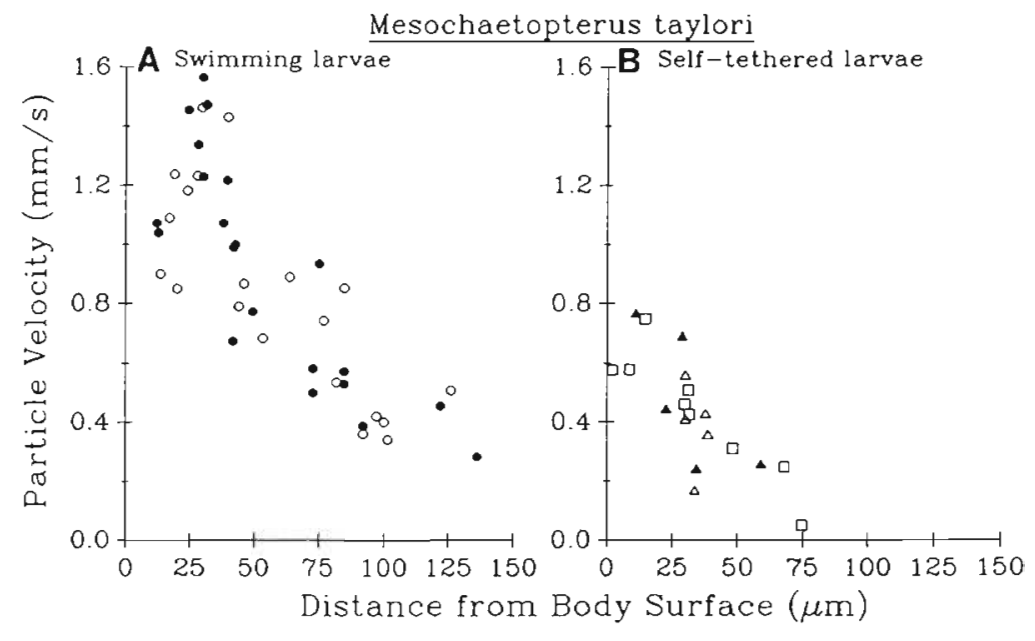

the velocity profile is constructed from the accumulation of measurements on particles passing a restricted region of the ciliated band, the velocity profile can be considered as an estimate of mean water velocity at all distances out from the surface of the larva. The area enclosed by the velocity profile, from the surface of the larva out to a distance equal to the length of cilia and bounded by the straight line perpendicular to the larva's surface (across which the particle velocities were measured), represents the amount of fluid passing through the ciliated layer in a unit of time. This area multiplied by a unit length of ciliated band yields a volume per unit time that passes a unit length of ciliated band. 
Table 3A. Mesochaetopterus taylori. Cilium lengths and angular velocities for freely swimming and tethered larvae. The numbers in each column are means, SD, and (sample size). Arc of radius and angular velocities for swimming and tethered larvae were compared with a Mann-Whitney U-test

\begin{tabular}{|c|c|c|c|}
\hline & Swimming larva & Tethered larva & Statistic \\
\hline \multicolumn{4}{|l|}{ Cilium length $(\mu \mathrm{m})$} \\
\hline Prototroch cilia & $42 \pm 1.5(5)$ & $35 \pm 3.1(4)$ & $\mathrm{U}=20, \mathrm{p}<0.05$ \\
\hline Metatroch cilia & $36 \pm 1.5(5)$ & $30 \pm 2.6(4)$ & $\mathrm{U}=20, \mathrm{p}<0.05$ \\
\hline \multicolumn{4}{|c|}{ Cilium angular velocity ( $\mathrm{rad} \mathrm{s}^{-1}$ ) } \\
\hline Prototroch cilia & $70 \pm 8(6)$ & $52 \pm 8(5)$ & $\mathrm{U}=28, \mathrm{p}<0.05$ \\
\hline Metatroch cilia & $114 \pm 8(5)$ & $85 \pm 22(5)$ & $\mathrm{U}=24, \mathrm{p}<0.05$ \\
\hline
\end{tabular}

Table 3B. Mesochaetopterus taylori. Regression information

\begin{tabular}{|lrrr|}
\hline Condition & Equation & $\mathrm{p}$ & \\
\hline Cilium/Particle velocity $(\mathrm{Y})$ vs Distance from surface $(\mu \mathrm{m})(\mathrm{X})$ & & $<0.001$ & $\mathrm{n}$ \\
Swimming larvae & $\mathrm{Y}=0.051 \mathrm{X}+0.76$ & 0.654 & $<0.005$ \\
Tethered larvae & $\mathrm{Y}=0.196 \mathrm{X}-0.77$ & 0.839 & 8 \\
Comparison of slopes for these regressions: $\mathrm{F}=22.678, \mathrm{p}<0.001$ & & \\
\hline
\end{tabular}

Because no significant slope was found for particle velocity as a function distance within the ciliated layer for Crassostrea gigas, the mean velocity was used to estimate volume flux through the ciliated region. Because the distance range of data that were available was restricted to the outer half of the ciliary layer (50 to $92 \mu \mathrm{m}$ out from the surface), estimation of the volume flux is restricted to this region (Table 4). Results indicate that when ciliary speeds remain unchanged, a tether on a larva reduces volume flux through the ciliated band.

If flux through the ciliary layer for the tethered larva is lower in still water than in flowing water, then on a single cilium stroke, water and particles in the ciliary layer should not move as far in still water as they do in flowing water. The relative motion between cilia and particles should be greater for the tethered larva in still water. The relative velocity of the cilium and particle at a given height above the surface of the larva was determined (see footnote $b$ in Table 1). Relative velocity within the ciliary layer was plotted as a function of distance from the surface of the organism (Fig. 5). An analysis of covariance (ANCOVA) indicated that slopes were not different for the tethered larva in flowing water and that in still water, but intercepts were different (Table 1A). Tethering a larva in still water increased the relative velocity of particles to cilia.

The volume flux of water relative to the cilia was estimated, in a manner analogous to the above estimate of volume flux through the ciliary layer. Linear regressions based on the common slope from the ANCOVA were fitted to the data and used to estimate the mean relative velocities within the ciliated layer for the cases of flow and no-flow. The areas under the regression lines from the surface of the larva out to a distance equal to the length of the cilia represent the amounts of fluid moving relative to the cilia in a unit of time. These areas multiplied by a unit length of ciliated

Table 4. Crassostrea gigas. Estimated volume fluxes through the ciliary region for a pediveliger larva. Estimates indicate the volume $\mathrm{s}^{-1}$ passing a $1 \mu \mathrm{m}$ length of ciliary band, in the region $50 \mu \mathrm{m}$ out from the surface to the tips of the cilia at $92 \mu \mathrm{m}$

\begin{tabular}{|c|c|c|c|}
\hline & Flow & No-Flow & $\begin{array}{l}\% \text { change from } \\
\text { Flow to No-Flow }\end{array}$ \\
\hline $\begin{array}{l}\text { Volume flux of water moving } \\
\text { past the organism }\left(\mathrm{mm}^{3} \mathrm{~s}^{-1}\right) \text { (A) }\end{array}$ & $3.48 \times 10^{-4}$ & $2.74 \times 10^{-4}$ & -21 \\
\hline $\begin{array}{l}\text { Volume flux of water moving } \\
\text { relative of cilia }\left(\mathrm{mm}^{3} \mathrm{~s}^{-1}\right)(\mathrm{B})\end{array}$ & $1.27 \times 10^{-4}$ & $2.25 \times 10^{-4}$ & +77 \\
\hline $\begin{array}{l}\text { Proportion of water moving past } \\
\text { organism that cilia shear through (B/A) }\end{array}$ & $36.5 \%$ & $82.1 \%$ & \\
\hline
\end{tabular}




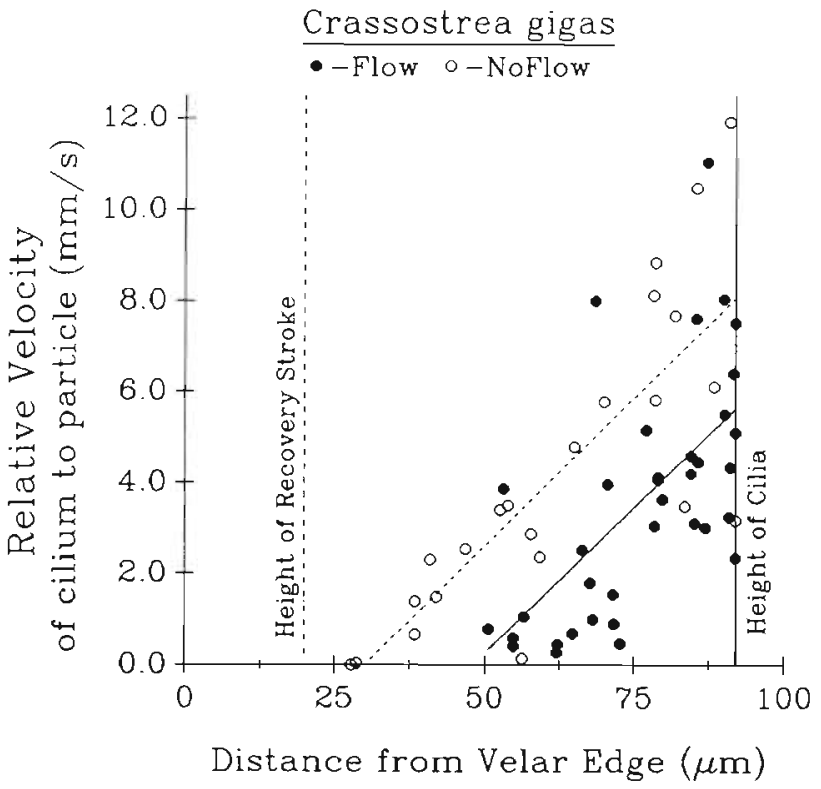

Fig. 5. Crassostrea gigas. Relative velocity of cilia to particles versus distance from the velar surface

band yield the volumes of fluid that pass cilia along a unit length of ciliated band in a unit of time. For purposes of comparison with volume flux through the ciliary layer, the volume of fluid moving relative to the cilia was determined over a region from $50 \mu \mathrm{m}$ out to the cilia tips (Table 4). In still water the tethered larva had ca $77 \%$ greater volume flux relative to the cilia than in flowing water. The increased volume flux relative to the cilia is likely to increase direct contact between cilia and particles passing through the ciliated region (see 'Discussion').

\section{Relative shear around cilia}

Crassostrea gigas and Calliostoma ligatum. Another way to examine the differences in relative movement of particles and cilia is to determine the ratio of cilium velocity to particle velocity for particles passing through the ciliary layer. To compare the shear of water around cilia for tethered larvae in flowing and still water, the ratio of cilium velocity to particle velocity at a given distance from the surface of the larva was calculated from the data on particle velocities in the ciliated layer of the velum of Crassostrea gigas (Fig. $6 \mathrm{~A})$. This ratio is only an approximate estimate of shear because the distances between particles and nearby cilia vary; thus the relative movements of cilia and particles also vary. Also, because metachronal wavelengths could not be monitored simultaneously during filming, it is not possible to tell whether they changed during filming. When in still water the tethered larva had a greater shear of particles relative to cilia than when in flowing water. An ANCOVA indicated the slopes of the ratios of cilium velocity to particle velocity versus distance from the surface of the larva were not different. However the intercept was greater for the tethered larva when in still water than when in flowing water (Table 1B, Fig. 6A).

The ratio of cilium velocity to particle velocity is dimensionless and can be used as a measure of shear independent of speed. Even though ciliary angular velocities were different for the 2 cases of the tethered larva of Calliostoma ligatum, the ratios of cilium velocity to particle velocity can be compared. Because cilium angular velocity could not be measured for each passing particle that passed the larva of C. ligatum, the
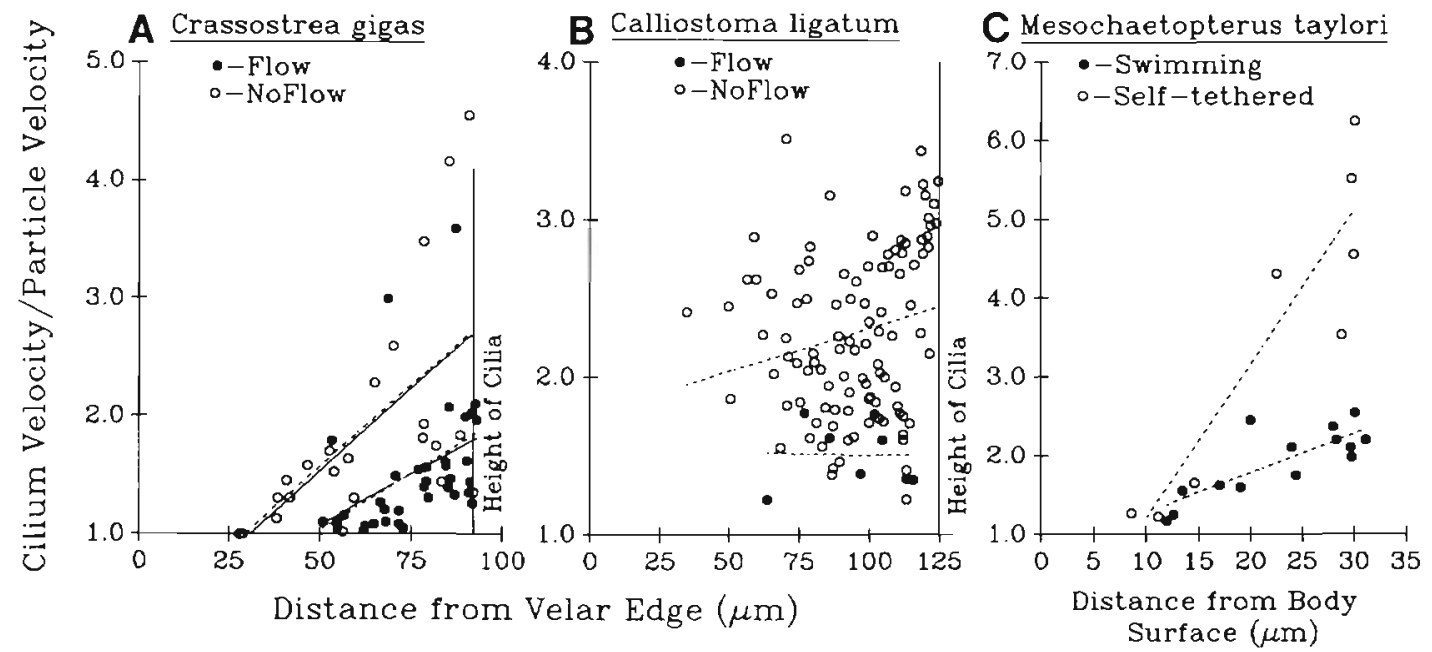

Fig. 6. Ratio of cilium velocity to particle velocity as a function of the distance from surface of the organism. (A) Crassostrea gigas. (B) Calliostoma ligatum. (C) Mesochaetopterus taylori. In (A), solid lines are linear regression lines based on cilium angular velocity measured with each passing particle. In (A), (B) and (C), dashed lines are regression lines based on mean cilium angular velocity. For regression equations see Tables 1 to 3 
mean cilium angular velocity for a film sequence was used to estimate cilium velocity. (The validity of using the mean angular velocity of cilia was first examined with data for Crassostrea gigas. The regressions of ratios of cilia velocity to particle velocity versus distance from the surface of the organism were essentially the same whether cilium velocity was determined from mean angular velocity or from actual angular velocity for a cilium associated with each particle [Table 1B, Fig. 6AJ). For the larva in still water there was a significant increase in this ratio as a function of distance from the velar edge to the tips of the cilia. In contrast, for the larva in flowing water, no significant relationship was found for this ratio as a function of distance from the surface (Table 2B, Fig. $6 \mathrm{~B}$ ). When the ratios of cilium to particle velocity were compared for the regions in the ciliary layer where the ranges of data overlapped, the ratio was significantly higher for the larva in still water (Table 2A), indicating greater shear of water past the cilia in still water.

Mesochaetopterus taylori. Shear of water around the cilia of freely swimming and self-tethered larvae of Mesochaetopterus taylori was also estimated using the mean angular velocity to calculate cilium velocity for the ratio of cilium velocity to particle velocity. Even though cilia were moving more slowly for the selftethered larvae of $M$. taylori compared to the freely swimming larvae, the estimated shear of cilia was greater for self-tethered larvae (Fig. 6C). The slopes of linear regressions of shear as a function of distance from the larval surface were significantly different for the swimming and self-tethered larvae (Table 3B).

\section{DISCUSSION}

The effects of tethering larvae include changes in particle trajectories, changes in the volume of fluid moved through the ciliary layer, and changes in the shear of cilia through surrounding water. These results have implications for (1) laboratory studies on tethered animals, (2) effects of zooplankton body shape and specific gravity on flow fields relative to beating cilia or appendages, and (3) effectiveness of suspension feeding by pelagic or sessile organisms that use the same or similar arrangements of fiberlike structures to produce the feeding current and to capture particulate food.

\section{Implications for laboratory tethering studies}

Because of the small size of zooplankton and even smaller size of their particulate food, studies on mechanisms of feeding require the use of microscopes and high-speed cinematography or videomicrography, and these in turn require tethering of organisms. The interpretation in the rest of this section applies to organisms that are normally free swimming during feeding but are tethered in stationary fluid for observation. This study showed that particles that pass through the ciliated layers come from a wider area upstream for tethered larvae than for non-tethered larvae. Similar parabolic particle trajectories have recently been reported for tethered larvae of the bivalve Mercenaria mercenaria (Gallager 1988). If particles are distributed evenly in the experimental environment, then curved trajectories of particles will not influence the number of particles passing through the cilia.

The consequences that tethering has for feeding will likely depend on the mechanism of feeding. Tethering results in reduced flux through the ciliated layer but increased movement of current-producing appendages relative to water. Larvae of echinoderms, enteropneusts, and possibly phoronids (Strathmann 1971, 1973, Strathmann \& Bonar 1976) concentrate food particles by a localized reversal of ciliary beat, triggered by the approach of particles that would ordinarily move through the ciliated layer. Reduced flux through the ciliated layer of these larvae brought about by tethering would be expected to reduce clearance rate of particles. In contrast, larvae of gastropods, bivalves, and some polychaetes feed with opposed bands of cilia that beat toward one another. Particles have been observed to pass through the upstream, prototrochal ciliated band and move into the food groove region which is just upstream from the metatrochal cilia (Strathmann et al. 1972, Strathmann \& Leise 1979). Though the mechanism(s) of particle capture is not known exactly, several hypothesized mechanisms involve the movement of prototrochal cilia relative to particles passing through the ciliated region (see Strathmann 1987, p. 483). Despite a reduced flux through the ciliated layer of a tethered larva, the increased shear of cilia relative to water may enhance the collection of particles that pass through the ciliated layer.

The comparison of the larva of Crassostrea gigas, tethered in still water and tethered in flow, showed that the amount of water through which cilia swept was $77 \%$ greater for the larva in still water (Table 4 ). The larva in still water swept through ca $80 \%$ of the volume of passing water compared to the ca $35 \%$ for larvae tethered in ambient flow (Table 4). Tethering, therefore, should increase the likelihood of direct interception of a particle by a cilium. The above conclusions are based on the assumption that ciliary velocity is not affected by tethering. If tethering reduces cilium velocity, volume flux through the ciliated layer would be reduced further, but shear of water that passes through the ciliated region may still be increased. Unfor- 
tunately, so few particle captures by tethered larvae of C. gigas were observed that a direct comparison between the 2 treatments cannot be made to determine the effects of tethering on clearance rates.

Gallager (1988) reported that larvae of Mercenaria mercenaria capture particles only when they pass through a restricted region of the ciliary layer just above the recovery stroke of preoral cilia. These observations are similar to those of Strathmann \& Leise (1979) who also noted a region within the ciliated layer where particles were more likely to be caught. Though his studies did not identify the mechanism of particle capture, Gallager (1988) made the additional observation that particles that were captured from this region had a clockwise rotation apparently related to the recovery stroke of the preoral cilia. Due to an absence of data on particles passing just above the recovery stroke region, the present study cannot determine whether the size of this capture region was affected by tethering. Neither can the data on the ratio of cilium to particle velocity be extrapolated into this region.

In conclusion, effects of tethering appear to introduce several changes in the flow field from the size scale of the organism to the scale of fibers that produce currents and function in particle capture. The effects of tethering will depend on the mechanisms of feeding used by a particular zooplankter. Tethering introduces quantitative changes in rates of flow and shear of fibers through water and thus limits the extrapolation of estimates of clearance rates based on these direct observations. On the other hand, there is no evidence to suggest that tethering changes the mechanisms used in particle capture. Future studies that employ tethering should attempt to incorporate the quantitative changes into conclusions that are drawn.

\section{Effects of zooplankton body shape and buoyancy on flow fields}

Strickler (1982) reported parabolic flows around freely swimming copepods Eucalanus crassus. The force of negative buoyancy balances the upward force generated by the feeding current so that E. crassus remains stationary (or moves slightly in the horizontal direction); this situation is equivalent to tethering. Because copepods are known to perceive approaching particles and change feeding currents to capture these particles (Koehl \& Strickler 1981, Price et al. 1983), curved flow fields allow the sampling of a greater area than that immediately in front of the animal and can increase the frequency of capturing food items (see also Strickler $1985 \mathrm{a}, \mathrm{b}$ ).

Generalizing Strickler's (1982) conclusions about effects of gravity and buoyancy, Emlet \& Strathmann
(1985) argued that both buoyancy and body drag are forces that retard organism movement through the water, and can alter the flow field by acting as partial tethers. Emlet \& Strathmann (1985) calculated that the tethering force of drag is expected to be of greater importance than gravity for the many zooplanktors with body lengths less than ca $0.5 \mathrm{~mm}$. Strickler (1985a) pointed out drag probably does not enhance feeding for large adult copepods such as Eucalanus crassus but may influence feeding by smaller nauplii or copepodites. The evidence presented in the present paper indicates how a force that retards forward motion can change the flow field and increase shear of water around the appendages producing a current. Because the drag force an animal experiences depends on its swimming speed, drag can act only as a partial tether, and effects on the flow field would not be as pronounced as those seen in this study. But as discussed above, any increased movement of appendages relative to particles may enhance feeding for zooplankters that use direct interception as a mechanism to capture particles.

Many zooplanktors, especially feeding larvae of marine invertebrates, have complex shapes with high surface area (e.g. Emlet \& Strathmann 1985, Emlet unpubl.). Large surface area and complex shape can increase drag and so may influence the flow field by changing particle trajectories and relative movement of appendages with respect to surrounding water. For example, as echinoid larvae grow they increase both the number and length of projections (larval arms) and these structures increase drag (Emlet 1983). These changes in body shape may change flow at the scale of the cilia producing the feeding current. A number of larvae or holoplankters also have spines or trail mucous strands that may act as sea anchors and change flow at the scale of appendages producing the feeding currents (e.g. Moyse \& Knight-Jones 1967, Hamner et al. 1975, Moyse 1984, reviewed in Strathmann 1987).

Some rotifers (e.g. Brachionis species) also exhibit polymorphisms in lengths of posterolateral spines (Gilbert 1980). Longer spines are known to be induced by low temperature and low food concentrations as well as by the predatory rotifer Asplanchna (Gilbert 1967, Halbach 1970). In a study comparing Brachionus calyciflorus with spines of differing lengths, Bogdan \& Gilbert (1982) found no significant difference in ingestion rates measured by uptake of radioactively labeled food particles. Whether there were differences in the ciliary apparati of the various rotifer groups or whether these groups showed differences in number of particles captured but not consumed remains unknown from that study.

The experimental organisms used in this study have cilia that beat and move water in planes virtually paral- 
lel to the swimming direction. Many organisms have appendages that move water in other planes, but still produce a velocity component that results in the movement called swimming. These organisms have complex flow fields often with balanced, radially or bilaterally symmetric flows. In one sense these complex arrangements of appendages can be thought of as tethered to one another and may produce radial flow fields with curved particle trajectories and enhanced shear of water relative to fibers. The effects of tethering on these radial flow fields have not been investigated experimentally.

\section{Implications for sessile suspension feeders}

Many of the effects of tethering should transfer directly to sessile suspension feeders because they are by definition tethered to a substratum. For a sessile suspension feeder relative to a pelagic one, with similar arrangements of fiberlike appendages, shear of the fibers through water would be increased while the volume moved through the fiber layer would be decreased. Again these changes would be expected to have different effects on suspension feeders, depending on the mechanism of particle capture used. Some rotifers can attach or swim freely while feeding and would offer an interesting comparison for the effects of tethering.

Sessile and pelagic modes of existence have evolved repeatedly among small, suspension-feeding organisms. Additionally many marine invertebrates have complex life histories with a pelagic larva that settles to become a sessile adult at a very small size. For some of these organisms the adult retains all or part of the larval feeding structures (e.g. inarticulate brachiopods and some phoronids). For other organisms, ciliary bands of larvae and adults are similar but the adult ciliary bands form newly at metamorphosis. The hydrodynamic changes that occur simply as a result of being tethered or free-swimming may have been important in directing the evolution of body form and location of fibers that produce feeding currents among these organisms. (For some benthic organisms, consequences of tethering may be obviated for small adults that settle where ambient currents are faster than their feeding currents.) Further investigations of flow fields around tethered and free swimming organisms combined with studies on feeding mechanisms will be required to make predictions that can be tested both experimentally and comparatively.

Acknowledgements. This research was supported by NSF grants OCE-8400818 to R. Strathmann and OCE-8510834 to M. A. R. Koehl. I thank T Daniel, S. Gallager, M. Koehl, A. Kohn, P. Mace, D. Pentcheff, and R. Strathmann for comments on earlier versions of the manuscript. Numerous discussions with T. Daniel, M. Koehl, and R. Strathmann were very helpful during the data collection and analysis of this study. I also thank the Director of Friday Harbor Laboratories, University of Washington, USA, for providing laboratory space and all of the above-mentioned people for use of various pieces of equipment. I thank Webb Camp Sea Farms, San Juan Island, WA, for providing oyster larvae, and P. Jumars for allowing use of the EXPERTVISION video analysis system.

\section{LITERATURE CITED}

Alcaraz, M., Paffenhöfer, G.-A., Strickler, J. R. (1980). Catching the algae: a first account of visual observations on filter feeding calanoids. Spec. Symp. Am. Soc. Limnol. Oceanogr. 3: 241-248

Bogdan, K. G., Gilbert, J. J. (1982). The effects of posterolateral spine length and body length on feeding rate in the totifer, Brachionus calyciflorus. Hydrobiologia 89 : $263-268$

Cazaux, C. (1965). Developpement larvaire de Chaetopterus variopedatus (Renier). Actes Soc. Linn. Bordeaux 102: $1-27$

Childress, S., Koehl, M. A. R., Miskis, M. (1987). Scanning currents in Stokes flow and the efficient feeding of small organisms. J. Fluid Mech. 177: 407-436

Emlet, R. B. (1983). Locomotion, drag and the rigid skeleton of larval echinoderms. Biol. Bull. 164: 433-445

Emlet, R. B., Strathmann, R. R. (1985). Gravity, drag, and the feeding currents of small zooplankton. Science 228: $1016-1017$

Fenchel, T (1986). Protozoan suspension feeding. Prog. Protistol. 1: $65-113$

Gallager, S. M. (1988). Visual observations of particle manipulation during feeding in larvae of a bivalve mollusc. Bull. mar. Sci. 43: $344-365$

Gilbert, J. J. (1967). Asplanchna and postero-lateral spine production in Brachionus calyciflorus. Arch. Hydrobiol. 64 : $1-62$

Gilbert. J. J. (1980). Further observations on the developmental polymorphism and its evolution in the rotifer Brachionus calyciflorus. Freshwat. Biol. 10: 281-294

Halbach, U. (1970). Die Ursachen der Temporalvariation von Brachionus calyciflorus Pallas (Rotatoria). Oecologia (Berl.) 4: $262-318$

Hamner, W. M., Madin, L. P., Alldredge, A. L., Gilmer, R. W. Hamner, P. P. (1975). Underwater observations of gelatinous zooplankton: sampling problems, feeding biology, behavior. Limnol. Oceanogr. 20: $907-917$

Jørgensen, C. B. (1966). Biology of suspension feeding. Pergamon Press, Oxford

Keller, S. R., Wu, T Y (1977). A porous prolate-spheroidal model for ciliated micro-organisms. J. Fluid Mech. 80: $259-278$

Koehl, M. A. R., Strickler, J. R. (1981). Copepod feeding currents: food capture at low Reynolds number. Limnol. Oceanogr. 26: 1062-1073

LaBarbera, M. (1984). Feeding currents and particle capture mechanisms in suspension feeding animals. Am. Zool. 24 $71-84$

Moyse, J. (1984). Some observations on the swimming and feeding of the nauplius larvae of Lepas pectinata Cirripedia: Crustacea). Zool. J. Linn. Soc. 80: 323-336

Moyse, J, Knight-Jones, E. W. (1967). The biology of cirripede larvae. Proc. Symp. on Crustacea, Emakulam, 1965, Pt 2. Mar Biol. Ass. India, p. 595-611 
Paffenhöfer, G.-A., Strickler, J. R., Alcaraz, M. (1982). Suspension feeding by herbivorous calanoid copepods: a cinematographic study. Mar. Biol. 67: 193-199

Price, H. J., Paffenhöfer, G.-A. (1985). Perception of food availability by calanoid copepods. Ergeb. Limnol. 21 $115-124$

Price, H. J., Paffenhöfer, G.-A., Strickler, J. R. (1983). Modes of cell capture in calanoid copepods. Limnol. Oceanogr. 28: $116-123$

Stevens, R. E. (1973). A thermodynamic analysis of mitotic spindle equilibrium at active metaphase. J. Cell Biol. 57: $133-147$

Strathmann, R. R. (1971). The feeding behavior of planktotrophic echinoderm larvae: mechanisms, regulation, and rates of suspension feeding. J. exp. mar. Biol. Ecol. 6: $109-160$

Strathmann, R. R. (1973). Function of lateral cilia in suspension feeding of lophophorates (Brachiopoda, Phoronida, Ectoprocta). Mar. Biol. 23: 129-136

Strathmann, R. R. (1987). Larval feeding. In: Giese, A. C., Pearse, J. S., Pearse, V. B. (eds.) Reproduction of marine invertebrates, Vol. 9. Blackwell Scientific, Palo Alto, p. $465-550$

Strathmann, R. R., Bonar, D. (1976). Ciliary feeding of tornaria larvae of Ptychodera flava (Hemichordata: Enteropneusta). Mar. Biol. 34: 317-324

This article was submitted to the editor
Strathmann, R. R., Leise, E. (1979). On feeding mechanisms and clearance rates of molluscan veligers. Biol Bull. mar. biol. Lab., Woods Hole 157: 524-535

Strathmann, R. R., Jahn, T L., Fonseca, J. R. C. (1972). Suspension feeding by marine invertebrate larvae: clearance of particles by ciliated bands of a rotifer, pluteus, and trochophore. Biol. Bull. mar. biol. Lab., Woods Hole 142: $508-519$

Strickler, J. R. (1982). Calanoid copepods, feeding currents and the role of gravity. Science 218: $158-160$

Strickler, J. R. (1985a). (Response to Emlet \& Strathmann 1985.) Science 228: 1017

Strickler, J. R. (1985b). Feeding currents in calanoid copepods: two new hypotheses. In: Lavarack, M. S. (ed.) Physiological adaptations of marine animals. Symp. Soc. exp. Biol. 23: 459-485

Werner, B. (1953). Beobachtungen über den Nahrungserwerb und die Metamorphose der Metatrochophora von Chaetopterus variopedatus. Helgoländer wiss. Meeresunters 4: 225-238

Wu, T. Y. (1977). Hydrodynamics of swimming at low Reynolds numbers. Bewegungsphysiologie-Biomechanik. Symp. Mainz Fortschritte der Zoologie 24: 149-169

Yule, A. B., Crisp, D. J. (1983). A study of feeding behavior in Temora longicornis (Muller) (Crustacea: Copepoda). J. exp. mar. Biol Ecol. 71:271-282

Manuscript first received: November 8, 1989

Revised version accepted: March 5, 1990 